\title{
OA09.01. Massage therapy for osteoarthritis of the knee: a randomized dose-finding trial
}

\author{
A Perlman ${ }^{1 *}$, A Ali $^{2}$, V Njike ${ }^{2}$, D Hom ${ }^{3}$, A Davidi ${ }^{2}$, S Gould-Fogerite ${ }^{4}$, C Milak $^{4}$, D Katz ${ }^{2}$ \\ From International Research Congress on Integrative Medicine and Health 2012 \\ Portland, Oregon, USA. 15-18 May 2012
}

\section{Purpose}

In a previous trial of massage for osteoarthritis (OA) of the knee, we demonstrated feasibility, safety and possible efficacy, with benefits that persisted at least 8 weeks beyond treatment termination.

\section{Methods}

We performed a RCT to identify the optimal dose of massage within an 8-week treatment regimen and to further examine durability of response. Participants were 125 adults with OA of the knee, randomized to one of four 8-week regimens of a standardized Swedish massage regimen (30 or 60 min weekly or biweekly) or to a Usual Care control. Outcomes included the Western Ontario and McMaster Universities Arthritis Index (WOMAC), visual analog pain scale, range of motion, and time to walk 50 feet, assessed at baseline, 8-, 16-, and 24-weeks.

\section{Results}

WOMAC Global scores improved significantly (24.0 points, 95\% CI ranged from 15.3-32.7) in the 60-minute massage groups compared to Usual Care (6.3 points, 95\% CI 0.1-12.8) at the primary endpoint of 8-weeks. WOMAC subscales of pain and functionality, as well as the visual analog pain scale also demonstrated significant improvements in the 60-minute doses compared to usual care. No significant differences were seen in range of motion at 8-weeks, and no significant effects were seen in any outcome measure at 24-weeks compared to usual care. A dose-response curve based on WOMAC Global scores shows increasing effect with greater total time of massage, but with a plateau at the 60-minute/ week dose.

'Duke University, Durham, USA

Full list of author information is available at the end of the article

\section{Conclusion}

Given the superior convenience of a once-weekly protocol, cost savings, and consistency with a typical realworld massage protocol, the 60-minute once weekly dose was determined to be optimal, establishing a standard for future trials.

\section{Author details}

${ }^{1}$ Duke University, Durham, USA. ${ }^{2}$ Yale University School of Medicine, Prevention Research Center, Derby, USA. ${ }^{3}$ Boston Medical Center, Boston, USA. ${ }^{4}$ University of Medicine and Dentistry of New Jersey, Newark, USA.

Published: 12 June 2012

\section{doi:10.1186/1472-6882-12-S1-033}

Cite this article as: Perlman et al:: OA09.01. Massage therapy for osteoarthritis of the knee: a randomized dose-finding trial. BMC Complementary and Alternative Medicine 2012 12(Suppl 1):033.
Submit your next manuscript to BioMed Central and take full advantage of:

- Convenient online submission

- Thorough peer review

- No space constraints or color figure charges

- Immediate publication on acceptance

- Inclusion in PubMed, CAS, Scopus and Google Scholar

- Research which is freely available for redistribution
C Biomed Central

\section{() Biomed Central}

